\title{
Foreword: Special Issue Micro 2017
}

\author{
Abhijit Biswas $^{1} \cdot$ Prabir Saha $^{2} \cdot$ Dulal Acharjee $^{3}$ \\ Published online: 10 June 2020 \\ (C) Springer-Verlag GmbH Germany, part of Springer Nature 2020
}

This Special Issue is dedicated to the recent advances in the emerging areas of Microelectronics, Circuits and Systems and their co-related fields. The topics covered electronic devices, circuits and systems, information storage, and also micro-electro-mechanical systems (MEMS) including sensors. Lately, extensive and notable research efforts have been put forward around the globe in order to advance these emerging fields, as well in the application of scientific knowledge and technology to the benefit of human society. Hence, this Special Issue was needed that would contain high-quality papers related to these promising areas.

The 4th International Conference on Microelectronics, Circuits and Systems (Micro 2017) was organized at Darjeeling, West Bengal, India during June 3-4, 2017 in which a total of 90 articles were presented. Out of these presentations extended and revised version of 37 good-quality papers were selected for submission to the Microsystem Technologies (MST). Authors of these selected papers were intimated to revise their manuscripts by adding at least 50\% novel and interesting research findings in the relevant topic alongside a different title before submission. All articles were subjected to rigorous peer review by at least two blind reviewers as per the norms of the Microsystem Technologies. On the basis of reviewers' comments the articles were revised by the authors, and then re-submitted. The revised papers were re-examined by the Guest Editors, and in some cases by the reviewers as well, and then the final publication decision on the paper was made. In this process 23 research articles were finally accepted for publication in this special issue. The published papers targeted different aspects as well as related fields of Microelectronics, Circuits and Systems: emerging electron devices such as hybrid FinFETs and circuits, information storage elements and circuits, MTJ-based non-volatile CAM cells, memristors, MEMS, low noise amplifier circuits, optical sensors, high performance nitride LEDs, generation of bioelectricity, piezoelectric energy harvester, and many more.

On behalf of the organizing committee of Micro 2017, we would like to express our sincere thanks to the authors for submitting extended version of their articles in this Special Issue. We express our sincere gratitude to all the reviewers who participated in the process. We appreciate the effort of the Editor-in-Chief of Microsystem Technologies for providing us the opportunity to publish the extended and revised version of some deserving papers of Micro 2017 in the Microsystem Technologies.

We are hopeful that this Special Issue will convey significant and valuable research information to the readers.

Publisher's Note Springer Nature remains neutral with regard to jurisdictional claims in published maps and institutional affiliations.

\footnotetext{
Abhijit Biswas

abiswas5@rediffmail.com

1 University of Calcutta, Kolkata, West Bengal, India

2 National Institute of Technology, Shillong, Meghalaya, India

3 Applied Computer Technology, Kolkata, West Bengal, India
} 